\title{
Facial expressions: An objective method in the quantitative evaluation of emotional change
}

\section{LEONARD RUBENSTEIN, ALLAN MEMORIAL INSTITUTE, DEPARTMENT OF PSYCHIATRY, MCGILL UNIVERSITY, Montreal, Canada ${ }^{I}$}

$A$ method is presented for obtaining a series of silhouettes that were analyzed as profiles of the human face. When depressed psychiatric patients smiled before and after electroshock therapy, a greater facial displacement was recorded after treatment. Controls did not show any trend in this regard.

This paper is an extension of our studies in the development of objective techniques for the measurement of changes in nonverbal communication in relation to emotional states. These include, for example, spectrum analysis of the human voice (Rubenstein, 1961, 1968), telemetric monitoring of human activity, and postural changes (Rubenstein, 1962; Cameron, Levy, \& Rubenstein, 1960).

In human communication, expressive movements of the face are a source of changing patterns of information. A dynamic evaluation of such patterns is described here. The assumption is that a facial expression at any instant can be measured objectively by representing the extemal appearance of the face as a family of profiles (or waveforms).

Figure 1 illustrates the idea of a family of profiles more clearly. Profile A divides the face into two parts and displays the familiar silhouette that alters its configuration with neck, chin, and mouth movements. Profile B, running through the eye, is a different shape and changes in accordance with the mobility of the cheek. Thus, the face can be divided into a number of discrete profiles, each changing its shape according to a particular facial expression.

Figure 2 shows a series of profiles, scanning from ear to nose, for one side of the face. The continuous line indicates a series of profiles recorded for a "relaxed" expression. Profiles were formed every 5 deg round the face, while the $S$ was told to relax and not to move. The dotted lines in the illustration indicate the change in each profile for a smile by the same $S$. It can be seen that in smiling, the cheek bulges characteristically (Fig. 2, Profiles 9 to 13) while below the nose (Profiles 17 to 21 ), the face tends to be drawn inwards with some interesting changes indicated by the undulating chinline.

Since Bell (1944), Darwin (1872), and Piderit (1925) first postulated that certain emotional states were associated with facial expressions, most investigators have focused their attention on the judging rather than the objective assessment of expressive qualities of the face (Woodworth \& Schlosberg, 1954). This may be due to the complexity of the problem at hand (Landis, 1924). The influence of such factors as breathing, food intake, speech, head and body movements, and external stimuli, tend to complicate analysis. The facial expression is constantly being molded and evaluated intuitively through an evolutionary learning process (Andrew, 1963), for it is the one part of the body that communicates the greatest amount of nonverbal information to the observer in the shortest possible time.

\section{METHODS}

The family of curves shown in Fig. 2 were recorded as follows: Ss, seated in a dental chair, were tilted back 30 deg from the vertical, shifting the center of gravity towards the head and shoulders, thus confining head movements mainly to the horizontal plane. A Bolex 16-mm motion picture camera, running

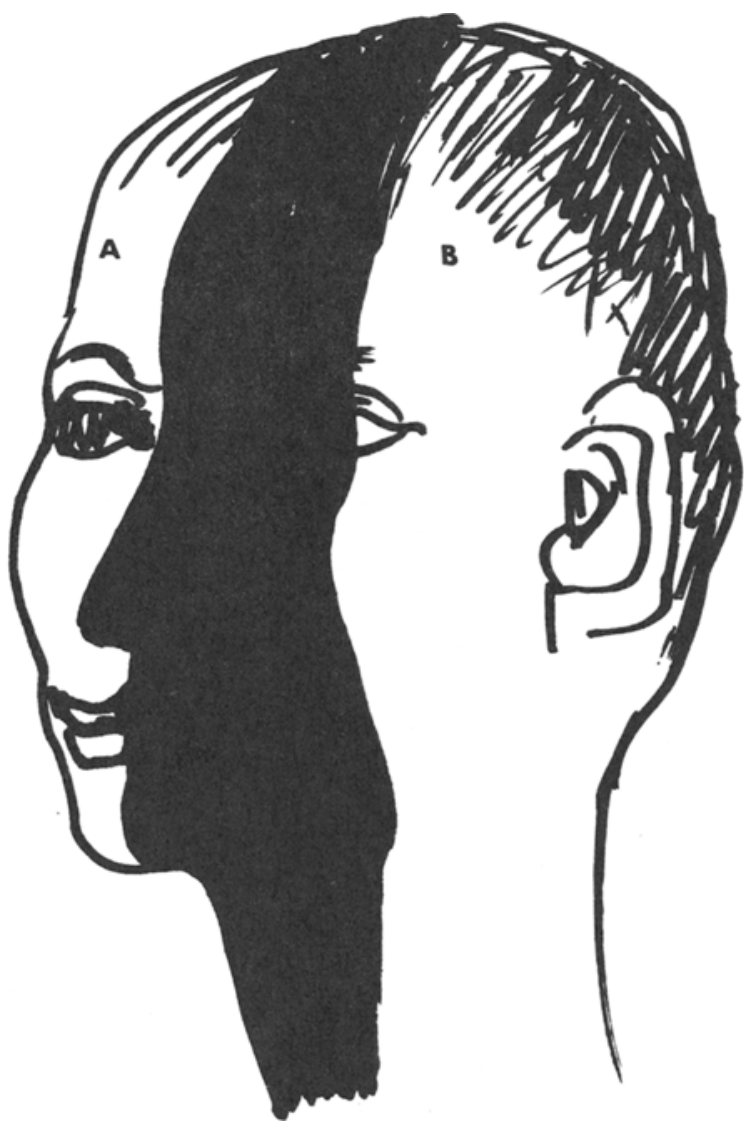

Figure 1

at 12 frames/sec, rotated at $12 \mathrm{rpm}$ on an inverted tripod mounted directly above the S's head. The camera lens was directed 120 deg down from the vertical. An arm, $4 \% / 2 t$ long, was rigidly connected to one end of the camera and carried a mirror at the other end. The arm rotated with the camera, around the $S$, at a height of $4 \mathrm{ft}$.

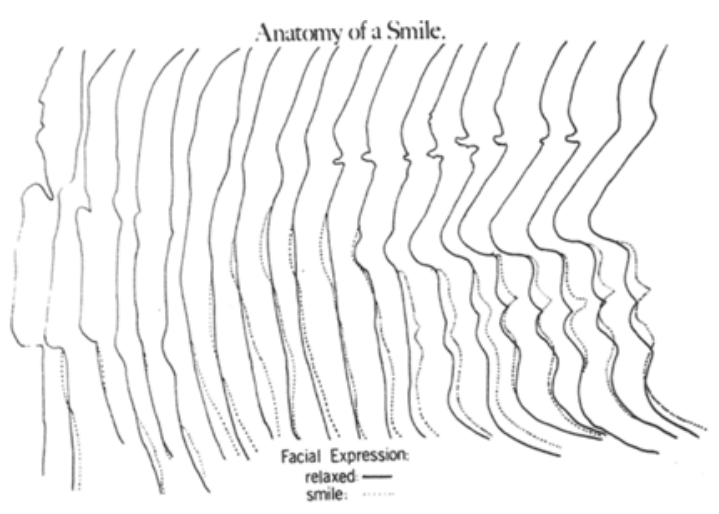

Figure 2 
At a radius of $5 \mathrm{ft}$, a 3-ft-high white cardboard background surrounded the $S$, except for an opening of 30 deg directly in front. Electronic flash tubes illuminated the background. Their flash sequence was controlled by a multicontact switch synchronized with the rotation of the camera. The mirror was adjusted so that an image of the S's face reflected into the 135-mm camera lens. As the camera-mirror combination rotated, different profiles of the $S$ were brought into view and were recorded on film by sequentially triggered flash tubes. Each frame of the 16-mm film contained one profile: white background, black face. Profiles for one side of the face were collected in $1.85 \mathrm{sec}$. In order to make sure that each series of profiles measured one expression, Ss were asked to "freeze" or hold an expression while measurements were taken. Profiles were recorded every $5 \mathrm{deg}$ of camera rotation. The film, after processing, was projected onto sheets of card, $22 \times 28$ in., and the outlines of the profiles were drawn by hand. Each profile was treated as a curve, and the area under it was measured with a planimeter. For this experiment, only the curves corresponding to profiles numbered 12 and 20, right side of face shown in Fig. 2, were computed.

In order to test the method, measurements were made on 16 female psychiatric patients in the $30-75$ age group, currently undergoing electroconvulsive therapy, in various depressive states and stages of treatment. Evaluations were made of the smile and were repeated within $1 \mathrm{~h}$ after treatment.

The Ss, seated in the dental chair, were asked to concentrate on an illuminated figure directly in front of them. The film was exposed and profiles recorded when they were asked to smile and to freeze the smile for a count of 10 . In order to guarantee the same head position for the before and after readings, the head was displayed on the ground glass of a $5 \times 7$ view camera and checked for orientation. In practice, it was found that the dental chair was so adjusted that Ss appeared to fall into an almost identical position for the second reading.

A control group of 16 females, having approximately the same age distribution, was measured twice during the course of a day with a 60 -min interval between readings.

\section{RESULTS}

As a group, 14 of the 16 psychiatric patients showed a greater facial displacement when smiling after treatment than before.
That is, the dotted line of Fig. 2 profiles, 12 and 20, showed a greater displacement after treatment with respect to the before-treatment smile. No significant displacement was evident in the control group.

This somewhat corroborates Kraines's (1957) view that an increased alertness and an improved diencephalic-rhinocephalic function is basic to the improvement in mood tones and is to be expected after ECT.

The results also indicate that facets of the complex shape of a facial expression at any instant may be described as a family of profiles that can be assessed objectively by integrating the profile waveforms and correlating them to a change in treatment of the psychiatric patient. This method may be considered a "dynamic" extension of Piderit's simple line drawings of a single profile (1925).

\section{REFERENCES}

ANDREW, R. J. Evolution of facial expression. Science, 1963, 142, 10341041.

BELL, C. H. Essay on the anatomy of expression in paintings. London: Longmans Green, 1944. P. 1806.

CAMERON, D. E., LEVY, L., \& RUBENSTEIN, L. Effects of repetition of verbal signals upon the behaviour of chronic psychoneurotic patients. Journal of Mental Science, 1960, 106, 742.

GEIGY COMPANY. Conference on methods of measurements in change in human behavior. Department of Psychiatry, McGill University, Montreal, September 27-28, 1962 (convened by the Geigy Co.).

DARWIN, C. Expressions of the emotions in man and animals. London: Murray, 1872.

KRAINES, S. H. Mental depressions and their treatment. New York Macmillan, 1957. P. 473.

LANDIS, C. Studies of emotional reactions. Journal of Comparative Psychology, 1924, 4, 447-501.

PIDERIT, T. Mimik und Physiognomik. (4th ed.). Detmold: Rejens, 1925.

RUBENSTEIN, L. Humming: A vocal standard with a diurnal variation. Science, 1961, 134, 1519-1520.

RUBENSTEIN, L. Continuous radio telemetry of human activity. Nature, $1962,193,849$.

RUBENSTEIN, L. Electronic analysis of nonverbal communication. Comprehensive Psychiatry, 1968, 9(3), 200-208.

WOODWORTH, R. S., \& SCHLOSBERG, H. Experimental psychology. New York: Holt, 1954. Pp. 111-120, 124-132.

\section{NOTE}

1. Present address: Psychiatry and Aging Research Laboratory, Veterans Administration Hospital, Albany, N.Y. 12208. 